\title{
Clinical severity and associated complications in pediatric patients with Guillain-Barré syndrome
}

\author{
Ángel Solana-Rojas ${ }^{1 *}$, Luis M. García-Melo², María D. Reyes-Varela ${ }^{3}$, Juan F. Díaz-Sotelo4, \\ Alfredo Cruz-Sánchez ${ }^{4}$, Juan C. Pérez-Moreno ${ }^{5,6}$, Francisco E. Basulto-López ${ }^{6}$, and Carolina Salinas- \\ Oviedo $^{7}$
}

${ }^{1}$ Emergency Department, Secretariat of Health and ${ }^{2}$ Neurology Department, Legaria Pediatric Hospital; ${ }^{3}$ Emergency Department, Coyoacán Pediatric Hospital; ${ }^{4}$ Intensive Pediatric Therapy Unit; ${ }^{5}$ Neurophysiology Department; ${ }^{6}$ Education Directorate, Legaria Pediatric Hospital; ${ }^{7}$ Education Directorate, Ruben Leñero Hospital, Mexico City, Mexico

\begin{abstract}
Background: Guillain-Barré syndrome (GBS) is an acute demyelinating polyradiculoneuropathy, of autoimmune origin, with heterogeneous clinical variants. It is the most frequent cause of flaccid paralysis in children. Incidence of 0.38-0.91 cases per 100,000, rare in children under 2 years. Objective: The objective of the study was to describe the clinical severity and complications in pediatric patients aged 1-18 years with GBS. Methods: A descriptive and retrospective analysis was carried out. We collected data from clinical files of patients of Legaria Pediatric Hospital with stellate ganglion block, period of 3 years (January 2015-December 2017). Results: Twenty-four patients, 18 men (75\%) and 6 women (25\%) were included in the study. The average age of 7.33 years (range: 1-16 years). School patients were the most affected (45.8\%). Nearly $62.5 \%$ had previous respiratory infection. The most frequent clinical variant was acute inflammatory demyelinating (62.5\%), axonal motor syndrome (29.2\%), and Miller Fisher syndrome (8.3\%). Nearly $16.7 \%$ presented dysautonomies requiring mechanical ventilation. Nearly $50 \%$ presented albuminocytological dissociation. The most frequent degree of clinical severity at admission was Grade IV on the Hughes scale (54.2\%). The degree of clinical severity most frequent at discharge was Grade II on the Hughes scale (33.3\%). Only $41.7 \%$ of patients received treatment with intravenous immunoglobulin (IVIG) at $1 \mathrm{~g} / \mathrm{kg} /$ day for 2 days. Conclusions: By means of contingency tables, the association between degree of severity at admission and discharge of GBS with respect to treatment with IVIG was determined. There is a 3.8 times greater risk of severity in patients without receiving the ideal treatment.
\end{abstract}

Key words: Guillain Barre. Pediatrics. Mechanic Ventilation.

\footnotetext{
Correspondence:

*Ángel Solana-Rojas

Emergency Department Legaria Pediatric Hospital

Calz. Legaria, No.371

Col. México Nuevo, Del. Miguel Hidalgo

Date of reception: 19-12-2018

Date of acceptance: 28-05-2019

E-mail: solanarojas.angel@gmail.com

DOI: 10.24875/RMN.19000014

Available online: 03-02-2020 Rev Mex Neuroci. 2020;21(1):15-26 www.revmexneurociencia.com 1665-5044/@ 2019. Academia Mexicana de Neurología A.C. Published by Permanyer. This is an open access article under the CC BY-NC-ND license (http://creativecommons.org/licenses/by-nc-nd/4.0/).
} 


\section{Severidad clínica y complicaciones asociadas en pacientes pediátricos con Síndrome de Guillain Barré}

\section{Resumen}

Introducción: El Síndrome de Guillain Barré (SGB) es una poliradiculoneuropatía desmielinizante aguda, de origen autoinmune, con variantes clínicas heterogéneas. Es la causa más frecuente de parálisis flácida en niños. Incidencia de 0.38-0.91 casos por 100,000, rara en menores de 2 años. Objetivo: Describir la severidad clínica y complicaciones en pediátricos de 1-18 años con SGB. Métodos: Se realizó un análisis de tipo descriptivo y retrospectivo. Se recabaron datos de expedientes clínicos de pacientes del Hospital Pediátrico Legaria con SGB, en un periodo de 3 años (enero 2015 - diciembre 2017). Resultados: Se incluyeron 24 pacientes, 18 hombres (75\%) y 6 mujeres (25\%). La edad promedio fue de 7.33 años (rango: 1-16 años). Los pacientes escolares fueron los más afectados (45.8\%). El 62.5\% tuvo infección respiratoria previa. La variante clínica más frecuente fue la desmielinizante inflamatoria aguda (62.5\%), el Síndrome Motor Axonal (29.2\%) y Síndrome de Miller Fisher (8.3\%). El 16.7\% presentaron disautonomias requiriendo ventilación mecánica. El 50\% presentó disociación albuminocitológica. El grado de severidad clínica más frecuente al ingreso fue el Grado IV en escala de Hughes (54.2\%). El grado de severidad clínica más frecuente al egreso fue el Grado II en escala de Hughes (33.3\%). Solo el 41.7\% de pacientes recibió tratamiento con inmunoglobulina intravenosa (Ig/V.) a $1 \mathrm{gr} / \mathrm{kg} /$ día por 2 días. Conclusiones: Mediante tablas de contingencia se determinó la asociación entre grado de severidad al ingreso y egreso del SGB respecto al tratamiento con IgIV, existiendo 3.8 veces mayor riesgo de severidad en pacientes sin recibir el tratamiento ideal.

Palabras claves: Guillain Barre en pediatría. Severidad clínica. Ventilación mecánica.

\section{Introduction}

Guillain-Barré syndrome (GBS) is an acute demyelinating polyradiculoneuropathy, of autoimmune origin, with heterogeneous clinical variants ${ }^{1}$. In most cases, there is a pattern of infection before the clinical manifestations of GBS (acute paralysis, paresthesia, and numbness). Moreover, progressive weakness of lower extremities with subsequent inability to ambulate ${ }^{1,2}$.

The first cases of GBS were described in 1857 by Landry, specifying that patients with GBS present ascending paralysis of motor predominance, respiratory failure, and death ${ }^{3,4}$. These clinical characteristics were delimited in 1916 by Guillain et al. ${ }^{4}$, demonstrating the presence of motor deficit and arreflexia, but with minimal or no sensory involvement. In addition, they established that albuminocytological dissociation is part of the comprehensive diagnosis of stellate ganglion block $(\mathrm{SGB})^{4}$.

In 1990, after the review of the SGB diagnostic criteria, Asbury and Comblath, they proposed electrodiagnostic criteria, the main characteristic being the delay in the conduction velocity of two or more motor nerves ${ }^{5}$.

GBS is the most frequent cause of flaccid paralysis in previously healthy children 6 . Worldwide, the annual incidence is $0.6-2.4$ cases per 100,000 inhabitants, in any age group, it affects both genders with an $\mathrm{H} /$ ratio. M 1.5:17.

For years worldwide, due to the introduction of vaccination schemes, there was a considerable decrease in the frequency of polio cases, with the eradication of this disease in some countries. In Mexico, the last reported case of poliomyelitis was October 18, 1990, in Jalisco. In April 1995, the wild poliovirus eradication certificate was granted in Mexico ${ }^{8}$. Therefore, after the reduction of polio cases, GBS disease became the main cause of acute flaccid paralysis (AFP) worldwide at all ages ${ }^{9}$.

During 1988 and 1996, in Mexico, within the framework of the global eradication of poliomyelitis and through the participation of the epidemiological surveillance system of the AFP, a study was conducted where 3730 cases of AFP were analyzed, specifying that $63 \%$ of the cases he had a final diagnosis of GBS, constituting since then the main cause of paralysis in patients under 15 years of age $^{10}$.

The epidemiology of GBS at the national level is unknown because there is little information available. Depending on the author consulted, the prevalence of GBS is diverse. In a study conducted at the National Institute of Pediatrics, during January 1988 and December 1996, GBS accounted for $77.9 \%$ of all acute flaccid paralyzes analyzed by the epidemiology service $^{11}$. The risk of developing GBS during the course of any patient's life is $<1: 1000^{12}$.

The main infectious agent reported in GBS outbreaks is Campylobacter jejuni ${ }^{13}$. Other infections associated with GBS are: Cytomegalovirus, Epstein-Barr virus, influenza A virus, Mycoplasma pneumoniae, and Haemophilus influenzae ${ }^{14}$. 
The clinical manifestations of the patient with classic GBS begin 2-4 weeks after an infectious episode (respiratory and/or gastrointestinal), presenting with acute weakness predominantly in the lower extremities, posterior caudocephalic dissemination, and in some cases compromise in bulbar or cranial nerves ${ }^{15}$.

The diagnosis of GBS is clinical. However, it can be complex in the population of preschool children due to an atypical clinical presentation, so the neurological examination must be thorough ${ }^{16}$. As mentioned, the clinical diagnosis is based on the latest update of the diagnostic criteria established by Asbury and Cornblath in $1990^{5,17}$. There are also specific biomarkers but many of these are not positive in some variants of GBS.

The GBS is defined clinically, anatomopathologically, and electrophysiologically as an acute inflammatory demyelinating polyneuropathy (AIDP). According to the characteristics of nerve conduction studies it was observed that GBS is characterized by; slowing of driving speeds, driving blockage, delayed latencies and/or scattered responses; but over time the evidence from several studies indicated that there are several clinical, serological, and electrophysiological characteristics in each of the GBS variants.

The following describes in detail the pathological anatomy, the antibodies present, and the symptomatology of each of the GBS variants:

a. In the acute inflammatory demyelinating type variant; there is involvement of motor roots ${ }^{18}$, notable segmental demyelination, infiltration of mononuclear cells predominantly $\mathrm{T}$ lymphocytes and macrophages in the peripheral nervous system, chains of sympathetic ganglia, and cranial nerves ${ }^{19}$. In addition to the proliferation of Schwann cells as part of the repair mechanism. There is an antibody cross-reaction against ganglioside GM1, finding axonal epitopes similar to the gangliosides present in $C$. jejuni (serotypes 19 and 41), whose polysaccharides are similar to the gangliosides located in the nerve, which would explain direct axonal damage and demyelination ${ }^{20}$. The main characteristic symptom of GBS is symmetric weakness in the lower extremities, decreased or absent deep tendon reflexes (arreflexia) and localized pain in the lower extremities or low back pain, which has been proven in $79 \%$ of the reported trials ${ }^{15}$

b. In the Miller Fisher syndrome (MFS) type variant; the findings found are very similar to those found in the PDIA. The main responsible is the ganglioside $G Q 1 b^{21}$, located in the myelin of cranial nerves, constituting the main ganglioside injured by specific antibodies cross-reactive by $C$. jejuni infections. The ganglioside GQ1b is considered a marker of ophthalmoplegia in SGB ${ }^{22,23}$. The anti-GT1 antibody is also a compromise marker and translates bulbar cranial nerve injury in $\mathrm{SGB}^{24}$. The classic triad of MFS is: ataxia, areflexia, and ophthalmoplegia in almost $50 \%$ of cases, diplopia, and/or facial paresis have been reported as the first clinical sign. In the case of external ophthalmoplegia, the first affected muscle is the superior rectus muscle, followed by paralysis of the lateral rectus muscle and finally the inferior rectus muscle is affected. It is characteristic in patients with MFS to appreciate the clinical phenomenon of bell ${ }^{25}$ c. In the axonal type variant, no inflammatory changes are seen; only a discrete primary lesion is found at the Ranvier nodes explaining the axonal degeneration. The anti-GD1a antibody is specific in this variant ${ }^{26}$. The clinical picture is not severe and depends on the extent of axonal injury. Unlike the classic variant of GBS, tendon reflexes are preserved and may even have hyperreflexia. In addition, if there is distal involvement, recovery is rapid and complete $^{25,27}$. Clarifying that, regardless of the variants of GBS, axons are the main target for autoimmune injury ${ }^{28}$.

The effect of immunotherapy in GBS has been studied for several years, based on several randomized controlled trials, establishing that the use of intravenous immunoglobulin (IVIG) and plasma exchange (plasmapheresis) is effective ${ }^{29}$.

The use of IVIG or plasmapheresis should be performed as soon as possible, ideally, start before there is irreversible nerve damage ${ }^{30}$.

The cornerstone of the treatment of GBS in pediatric patients is based on the use of IVIG. The treatment guidelines are divided according to the dose; $1^{\text {st }}$ guideline (most effective therapy): immunoglobulin dose ( $2 \mathrm{~g} / \mathrm{kg}$ of body weight) administered in 2 days at $1 \mathrm{~g} / \mathrm{kg} / \mathrm{day}$, and the $2^{\text {nd }}$ pattern: dose of immunoglobulin at $0.4 \mathrm{~g} / \mathrm{kg}$ of body weight administered in 5 days $\mathrm{s}^{2,31}$.

The administration of IVIG at $0.4 \mathrm{~g} / \mathrm{kg}$ in 5 days decreases the risk of cases of side effects ${ }^{32}$. However, the use of IVIG at a dose of $1 \mathrm{~g} / \mathrm{kg} /$ day for 2 days, effectively decreases the subsequent clinical complications with greater limitation of damage neuronal present in GBS, constituting the ideal treatment in pediatric patients ${ }^{33}$.

The specific indications for the use of IVIG are the following; rapid progression of muscle weakness, respiratory insufficiency or mechanical ventilatory support, bulbar or cranial nerve involvement and inability to ambulate ${ }^{2}$. 
In case of therapeutic use with plasmapheresis, five sessions will be required, each exchange will include 2-3 $L$ of plasma according to the patient's body weight with a treatment duration of 2 weeks, confirming the therapeutic benefit when treatment is initiated in the first 4 weeks (preferably in the first 2 weeks) from the start of $\mathrm{SGB}^{29}$.

Plasmapheresis has shown the same efficacy as immunoglobulin but is a more invasive treatment, being reserved only for cases of intolerance or poor response to the administration of $\mathrm{IVIG}^{32}$.

Therapy that was previously used based on corticosteroid doses does not show effectiveness in $\mathrm{SGB}^{32,34}$.

The clinical evolution of GBS is usually limited. Symptoms reach their maximum expression in the first 4 weeks after an infectious episode and a recovery period after months or years (secondary to the decrease in the immune response and the period during which the peripheral nerve performs an endogenous repair with limited of the box ${ }^{30}$.

The prognosis of GBS in children is generally good. More than $90 \%$ of the cases of the acute inflammatory demyelinating variant and all cases of MFS recover completely ${ }^{35}$. Cases of emergencies are when there is a delay in the diagnosis of GBS especially in young children ${ }^{16}$.

The severity of the clinical picture is important as a prognostic factor in GBS. About $40 \%$ of affected children have the inability to ambulate during the acute phase. In severe cases, approximately $25 \%$ of patients will require special support in intensive care units due to the need for support with artificial ventilation secondary to dysautonomias ${ }^{15,36-38}$.

After the natural evolution of the disease, it has been shown that $20 \%$ of patients with GBS will not be able to walk without support after 6 months of starting the clinical picture of $\mathrm{GBS}^{39}$. Therefore, it is important to establish predictive measures clinic, to improve care and establish an opportune treatment in patients with GBS.

In this way, it constitutes the fundamental role of rehabilitation therapy as a coadjutant treatment of patients with GBS. With which, it is allowed to reduce the cases of thrombophlebitis (mobilization and use of elastic bandages) and the subsequent damage of joints (using orthoses and splints). Muscle stimulation is essential to prevent or reduce the degree of muscle atrophy in patients with GBS.

The support established by respiratory and motor physiotherapy will aim to reduce the severity of muscle atrophy due to the prolonged paralysis present in GBS, with the final goal of having an early restoration of motor function with the reintegration of the patient to their autonomy and improve their quality of life ${ }^{12,33}$.

Because there are currently few studies on GBS in pediatrics, constituting a national public health problem (since it affects thousands of Mexican patients), the present work was aimed at; to describe the clinical severity and associated complications in pediatric patients with GBS in a concentration hospital in Mexico City.

\section{Methods}

The study carried out is descriptive and retrospective. Data were collected from the clinical files of patients admitted to Legaria Pediatric Hospital with a diagnosis of GBS, in a period of 3 years (January 2015-December 2017).

\section{Considering as inclusion criteria}

a.Complete clinical records of pediatric patients of male and female sex, with an age between 1 and 18 years of age

b. Previously healthy pediatric patients with a history of gastrointestinal and/or previous respiratory infection (2 weeks-1 month) before the onset of neurological symptoms (according to the clinical criteria of GBS established by Asbury)

c. Pediatric patients with clinical criteria characteristic of GBS (clinical criteria of GBS established by Asbury) and comprehensive assessment by the pediatric neurology service

d. Pediatric patients with an integral approach to GBS (laboratory and/or cabinet studies).

\section{Considering as exclusion criteria}

a.Complete clinical records of pediatric patients with previous neuropathy or lower motor neuron lesion, not compatible with GBS

b. Pediatric patients who do not have an adequate comprehensive approach to GBS (incomplete clinical file, laboratory studies, and/or incomplete cabinet).

\section{Finally, the elimination criteria}

Complete clinical records of patients who moved to another hospital unit during their hospitalization.

Pediatric patients who met the inclusion criteria on admission to the emergency department were evaluated by a pediatric neurologist, verifying that they met the 
clinical criteria of Asbury and Cornblath to be diagnosed with GBS.

All pediatric patients were requested to enter the hospital unit, as part of the comprehensive diagnostic protocol, the following laboratory studies; complete blood count, serum electrolytes ( $\mathrm{Na}, \mathrm{K}, \mathrm{Cl}, \mathrm{Ca}, \mathrm{Mg}$, and $\mathrm{P})$, creatine kinase (CK) and CK-MB levels, liver function tests (alanine aminotransferase, aspartate aminotransferase, and lactic acid dehydrogenase [LHD]), general urinalysis, and cerebrospinal fluid (CSF) study during your inpatient stay.

Complementary electrophysiological studies (neuroconduction studies) were also requested to classify each of the present clinical variants of GBS: acute inflammatory demyelinating, motor axonal, motor and sensitive, plus some axonal pattern as established by the International Federation Standards of Clinical Neurophysiology.

The evaluation of motor conduction was performed in the median, ulnar, tibial, and peroneal nerves, including the $F$ wave analysis. Sensory antidromic conduction studies were performed on the median, ulnar, and sural nerves. The patients were classified into three categories according to the electrophysiological criteria of Asbury and Cornblath: (1) AIDP; (2) acute motor axonal neuropathy (AMAN), when in the absence of demyelination parameters, amplitudes of distal composite muscle action potentials $<80 \%$ of the lower normal limit in two or more motor nerves were recorded; and (3) acute motor-sensory axonal neuropathy, when with the AMAN pattern there was also a decrease in the amplitude of the sensory nerve action potentials $<50 \%$ of the lower normal limit in two or more nerves.

During the study, each of the following variables were analyzed: age, sex, preceding factors (previous gastrointestinal and/or respiratory infections, surgery, toxins, and vaccination), and time elapsed since the event or previous pathology and the onset of symptoms, manifestations clinics, analysis of laboratory studies, CSF study, ventilatory mechanical support and duration of the same, length of in-hospital stay, degree of severity at admission and discharge, clinical variant of the disease, in-hospital clinical evolution, and medical treatment established (steroids, immunoglobulin, plasmapheresis, etc.).

Subsequently each of the pediatric patients were examined and classified according to the functional disability scale for GBS of Winer and Hughes (0: normal; 1: minor signs or symptoms, able to run; 2: can walk $5 \mathrm{~m}$ without help, independently; 3: can walk $5 \mathrm{~m}$ with a walker or similar support; 4: cannot walk, stays in bed, or wheelchair, 5: requires mechanical ventilation, and 6: death). CSF analysis was performed, with determination of cells, glucose, total proteins, and presence of protein-cytological dissociation.

The descriptive statistical analysis was carried out, where media and standard deviation (SD) are used for the quantitative variables (days of stay), and for the qualitative ones (assisted mechanical ventilation) frequencies and percentages are used.

In the inferential statistical analysis, the Chi-square was determined to establish whether there is an association between the degree of clinical severity of GBS and the support of mechanical assisted ventilation. The percentage of patients was determined according to the association between the degree of clinical severity and the support of mechanical ventilation.

The student's t-test was applied to compare the means of the continuous quantitative variables of normal distribution and to determine the relationship between the degree of clinical severity of GBS on admission with respect to the degree of clinical severity of GBS at discharge.

Regarding the continuous quantitative variables, they will be described as arithmetic mean and SD, as well as the rank that corresponded to a normal distribution or a non-parametric distribution, respectively.

Contingency tables were made to determine the association between the degree of clinical severity of GBS on admission and discharge with respect to the ideal medical treatment (IVIG $1 \mathrm{~g} / \mathrm{kg} /$ day for 2 days).

All $p$-values for comparisons were calculated to two tails and considered significant when $p<0.05$. The statistical package SPSS v 20.0 was used in all calculations.

\section{Results}

During a period of 3 years (January 2015-December 2017) in the Legaria Pediatric Hospital of Mexico City, a referral hospital for neurological pathologies, 24 patients met the inclusion criteria established for this research work (criteria based on in guidelines and/or international protocols for the diagnostic and therapeutic approach of GBS in pediatrics).

Of the 24 cases that met the inclusion criteria, the frequency according to sex was 18 cases of the male gender and six of the female gender. The percentage according to sex was $75 \%$ of the male sex and $25 \%$ of the female sex. The average age was 7.33 years. The age range was 15 years, the youngest patient was 1-year-old, and the largest patient was 16-years-old. 
The group of patients most affected with GBS according to age was that of school children (5-11 years) with a frequency of 11 patients and an average of $45.8 \%$.

Of the 24 cases, $15(62.5 \%)$ had a history of respiratory infection; 5 (20.8\%) had gastrointestinal infection, $4(16.7 \%)$ had no history of the previous infection, and $0(0 \%)$ received previous vaccination (immunization).

The average time between the preceding factors (respiratory, gastrointestinal infection, no previous infection, or vaccination) and the onset of the clinical symptoms of GBS was 8.71 days (range of 27 days, minimum 1 day, and maximum 28 days).

In patients who had a previous respiratory infection, the period of time elapsed at the onset of symptoms of GBS was 10.13 days (range 27 days, minimum 1 day, and maximum 28 days).

Patients with a history of gastrointestinal infection, during the period of time elapsed at the onset of symptoms of GBS was 9.60 days (range 7 days, minimum 7 days, and maximum 14 days).

In the case of patients with no history of the previous infection, the period of time elapsed at the onset of symptoms of GBS was 2.25 days (range 5 days, minimum 1 day, and maximum 6 days).

The main clinical signs that appeared in the patients on admission to the hospital unit were: weakness in the lower extremities 22/24 (91.66\%) and diminished tendon reflexes in the lower extremities 22/24 (91.66\%).

The time elapsed between the onset of the symptoms of GBS and the clinical diagnosis of GBS was on average 1.88 days (range 5 days, minimum 1 day, and maximum 6 days).

The most frequent clinical variant of GBS, in our group of patients, was the acute inflammatory demyelinating with 15 cases $(62.5 \%)$, the axonal motor syndrome variant with 7 cases $(29.2 \%)$, and finally the MFS with 2 cases $(8.3 \%)$.

The cranial nerves that suffered the most affection were the III, IV, and VI cranial nerve, occurring in up to two patients $(8.32 \%$ of cases).

Within the in-hospital clinical evolution, four patients (16.7\%) presented with dysautonomies characterized by tachycardia or bradycardia.

The average number of days of in-hospital stay was 16 days (range 50 days, minimum 4 days, and maximum 54 days).

All the patients underwent laboratory studies as part of the comprehensive protocol and approach.

The studies carried out were blood count, blood chemistry, serum electrolytes, liver function tests, CK and CK-MB exhaust enzymes, general urinalysis, and acute phase reactants.

In $100 \%$ of the laboratory studies, normal results were reported.

In $50 \%$ of the patients, when lumbar puncture was performed, they presented albuminocytological dissociation (hyperproteinorrachia or proteins $>50 \mathrm{mg} / \mathrm{dl}$ and/or cells $<10 \mathrm{~mm}^{3}$ ).

The average days between the beginning of the GBS and the lumbar puncture were with an average of 3.13 days, with a range of 13 days. The earliest lumbar puncture was on the $1^{\text {st }}$ day of hospitalization and the later one at 14 days of hospitalization.

Regarding the neuroconduction study (study of support for the confirmation of the clinical variant of GBS), the average between the time of the initial clinical manifestations of GBS and the performance of the neuroconduction study was on average 9.46 days (range 56 days, minimum 1 day, and maximum 57 days).

According to the neuroconduction study, the most frequent clinical variant of GBS was the acute inflammatory demyelinating type with a frequency of $15(62.5 \%)$, followed by the axonal motor variant with a frequency of $7(29.2 \%)$ and finally the Miller Fisher variant with a frequency of $2(8.3 \%)$.

The degree of clinical severity more frequent in patients on admission to the hospital unit was Grade IV (confined to bed) based on the Hughes scale, with 13 patients being affected (54.2\%) (Fig. 1).

The degree of clinical severity more frequent in patients on discharge from the hospital unit was Grade II (walk more than $5 \mathrm{~m}$ without help or support but not jump or perform daily activities) based on the Hughes scale, eight patients being affected (33.3\%) (Fig. 1).

The average of the different medical treatments used according to availability in the hospital unit were: 1 = steroid (methylprednisolone (dose $30 \mathrm{mg} / \mathrm{kg} /$ day for 3 days) 2/24 (8.3\%), 2 = IVIG (dose $1 \mathrm{~g} / \mathrm{kg} /$ day for 2 days) 10/24 (41.7\%), 3 = IVIG (400 mg/kg/day dose for 5 days) 3/24 (12.5\%), 4 = IVIG (suboptimal dose < $2 \mathrm{~kg} / \mathrm{kg} /$ day or $<400 \mathrm{mg} / \mathrm{kg} /$ day) $6 / 24(25 \%), 5$ = plasmapheresis $0 / 24(0 \%)$, and $6=$ supports measures $3 / 24$ (12.5\%) (Fig. 2).

The average time between the onset of clinical manifestations of GBS and the start of hospital treatment with a steroid (methylprednisolone $30 \mathrm{mg} / \mathrm{kg} /$ day for 3 days) was on average 7 days (range 2 days, minimum 6 days, and maximum 8 days).

The average time between the onset of the clinical manifestations of GBS and the start of hospital treatment with IVIG ( $1 \mathrm{~g} / \mathrm{kg} /$ day for 2 days) was on average 
A

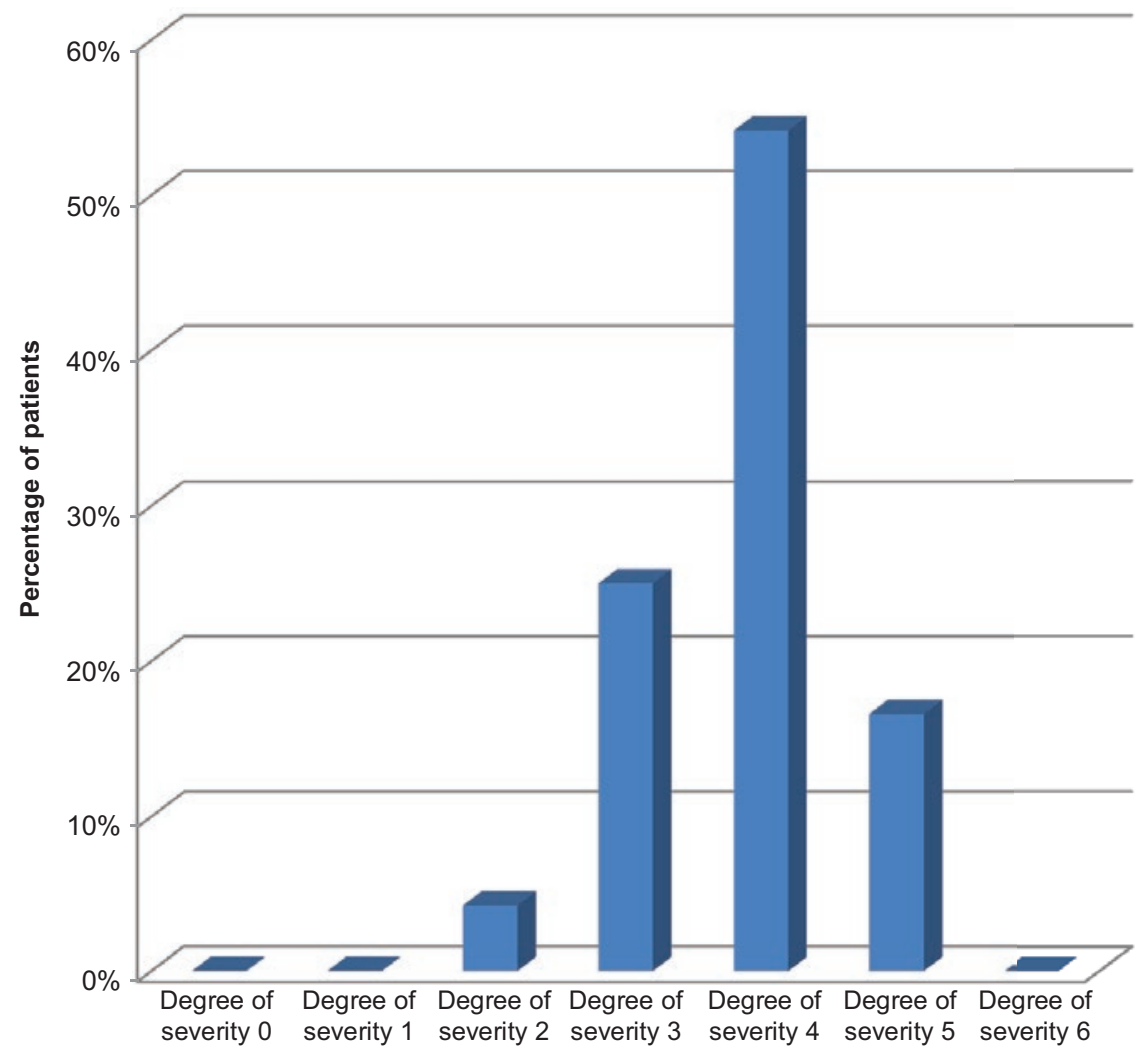

Degree of severity upon admission (Hughes scale $=6$ degrees of severity) $(0=$ healthy $)(1=$ mild signs and symptoms, daily activities) $(2=$ Walk more than $5 \mathrm{~m}$ without help but do not jump or perform daily activities) $(3=$ Walk more than $5 \mathrm{~m}$ but
with help) $(4=$ Bed confined $)(5=$ Partial or total mechanical ventilation) $(6=$ Death $)$

B

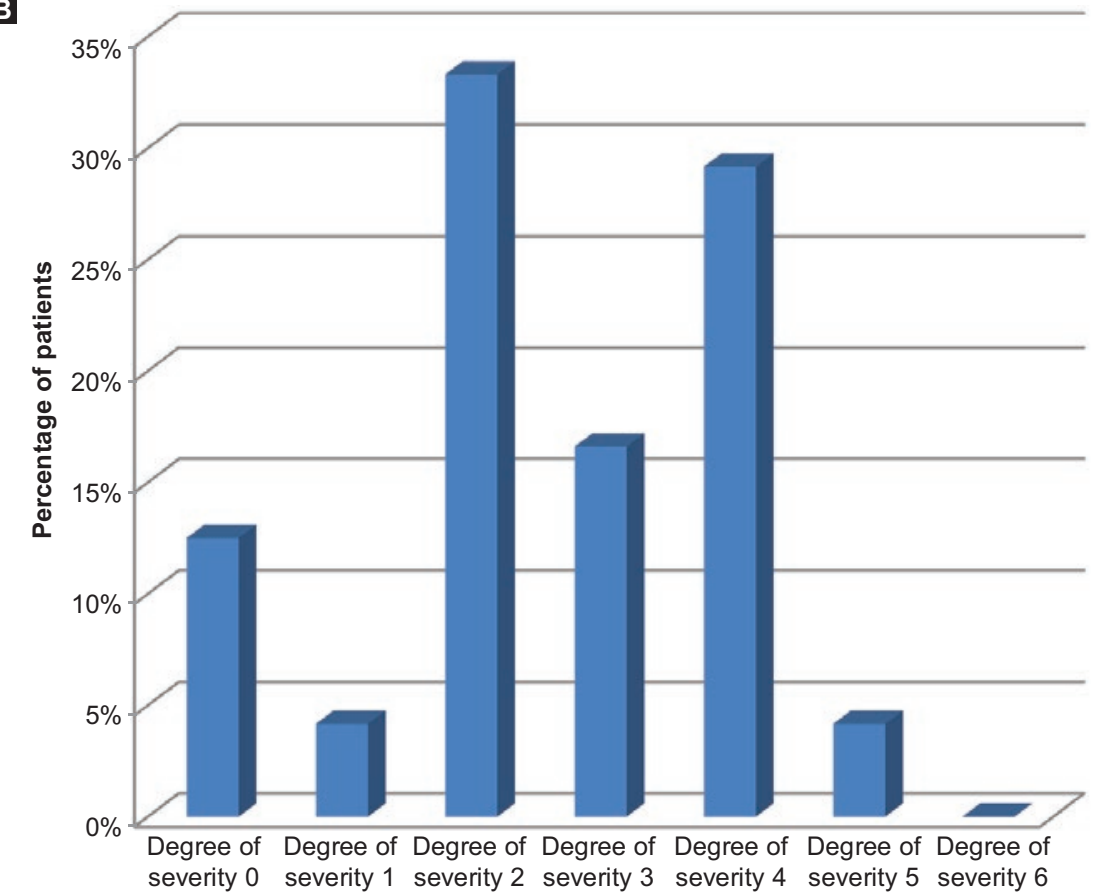

Degree of severity at discharge (Hughes scale $=6$ degrees of severity $)(0=$ healthy $)(1=$ mild signs and symptoms, daily activities $)$ ( 2 = Walk more than $5 \mathrm{~m}$ without help but do not jump or perform daily activities) ( $3=$ Walk more than $5 \mathrm{~m}$ but with help) $(4=$ Bed confined $)(5=$ Partial or total mechanical ventilation $)(6=$ Death $)$

Figure 1. Percentage of patients according to the Hughes severity scale of Guillain-Barré syndrome at hospital admission (A) and hospital discharge (B) (source: Clinical record. Legaria Pediatric Hospital. Secretariat of Health of Mexico City). 


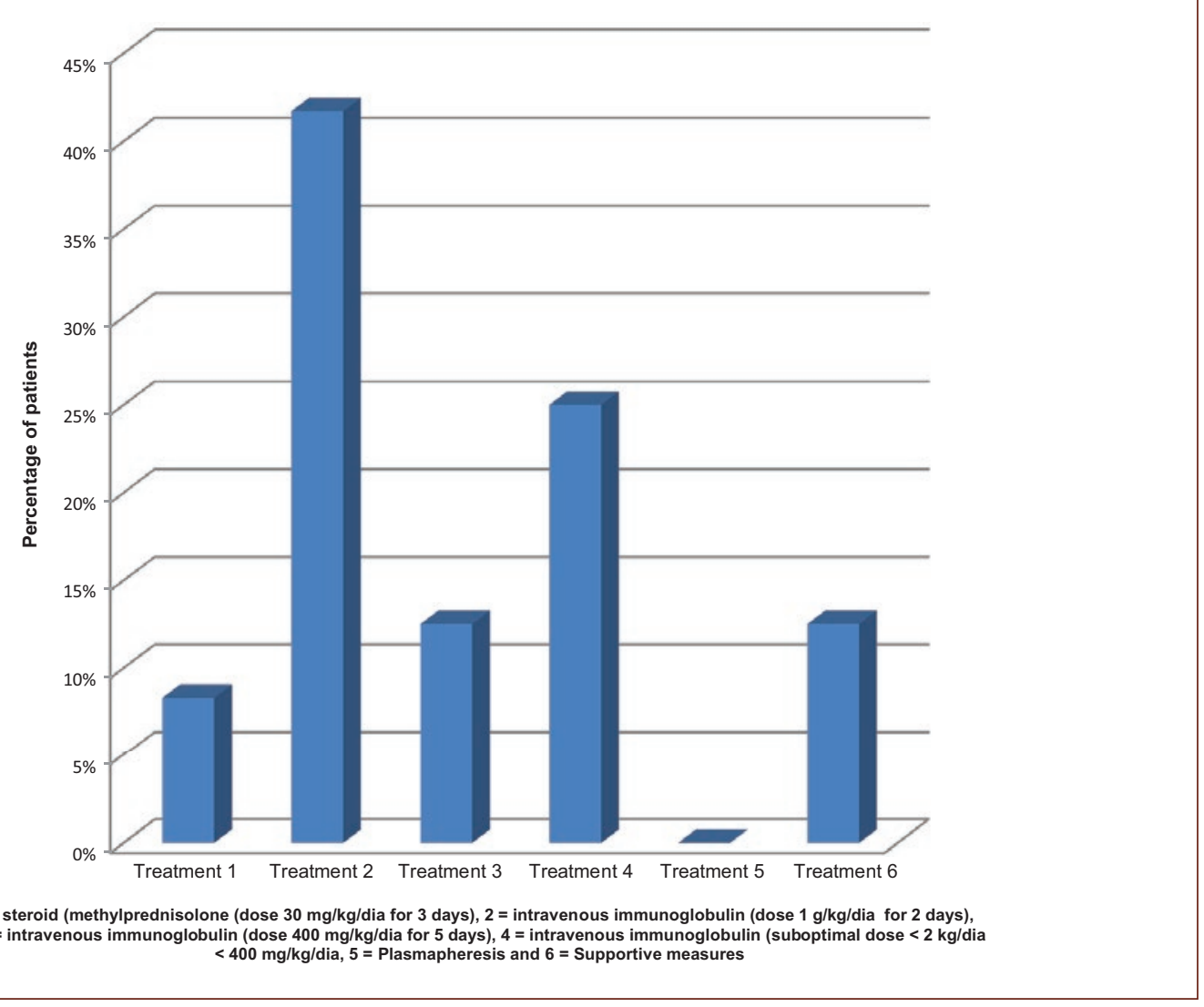

Figure 2. Percentage of patients according to the medical treatment in the Guillain-Barré syndrome according to availability in the hospital (source: Clinical record. Legaria Pediatric Hospital. Secretariat of Health of Mexico City).

4 days (range 10 days, minimum 1 day, and maximum 11 days).

The average time between the onset of clinical manifestations of GBS and the start of hospital treatment with IVIG (400 mg/kg/day for 5 days) was on average 4 days (range 4 days, minimum 2 days, and maximum 6 days).

The average time between the onset of the clinical manifestations of GBS and the start of inpatient treatment with IVIG (suboptimal dose) was on average 2.5 days (range 6 days, minimum 1 day, and maximum 6 days).

The time between the onset of GBS and the start of hospital treatment with supportive measures was on average 1 day.

According to the clinical evolution during the inpatient stay, $16.7 \%$ of the patients (4/24) required assisted mechanical ventilation, reporting an average of 2.25 days between the onset of the clinical manifestations of GBS and the need for support with mechanical ventilation according to the patient's clinical conditions (range 4 days, minimum 1 day, and maximum 5 days).
Of the four patients who needed assisted mechanical ventilation, the average duration of ventilatory support was 29.75 days (range 13 days, minimum 23 days, and maximum 36 days).

According to the clinical evolution, the four patients that required assisted mechanical ventilation (16.7\%) presented respiratory muscle and/or bulbar involvement, this being an absolute indication for it (Phase III mechanical ventilation).

Of the four patients who required mechanical ventilatory support; one-fourth ( $25 \%$ of cases) required orotracheal intubation without requiring tracheostomy and/ or gastrostomy due to clinical improvement, presenting adequate suction and swallowing reflex and absence of respiratory distress. One-fourth ( $25 \%$ of the cases) required a tracheostomy but no gastrostomy, presenting an adequate clinical evolution and weaning of mechanical ventilatory support. Two-fourth ( $50 \%$ of cases) required surgical intervention with tracheostomy and gastrostomy due to poor clinical evolution, with subsequent weaning of the ventilator, but in all three cases 
of patients requiring tracheostomy $(75 \%)$ all required support of supplemental oxygen at home discharge.

During the hospital stay, five patients $(20.8 \%)$ developed nosocomial infection characterized by pneumonia associated with health care and 19 patients did not develop intrahospital infection (79.2\%).

It was determined whether the degree of clinical severity of GBS constitutes a risk factor for assisted mechanical ventilation.

Of the 24 patients, eight were classified in the group with the highest degree of severity of GBS (Grades IV, $\mathrm{V}$, or VI established by the Hughes severity scale), and 16 patients belonged to the group with the lowest degree of severity of GBS (Grades 0, I, II, and III established by the Hughes severity scale).

Of the eight patients with greater degree of severity of GBS, $4(50 \%)$ required assisted mechanical ventilation, and the remaining $4(50 \%)$ did not require assisted mechanical ventilation (Fig. 3).

The 16 patients with a lower degree of severity of GBS did not require assisted mechanical ventilation. We obtained a Chi-square $9.60 p<0.01$, establishing that there is a significant difference; there is an association between the degree of clinical severity and the assisted mechanical ventilation (Table 1).

Regarding the degree of clinical severity of GBS at admission related to the degree of clinical severity of GBS at discharge, a Student's T-test of 5933 was obtained, with $p<0.001$; there is a statistically significant difference between the degree of severity at admission versus patient discharge (Table 2 and Fig. 4).

The association between the degree of clinical severity of GBS on admission and the ideal medical treatment (IVIG $1 \mathrm{~g} / \mathrm{kg} /$ day for 2 days) was obtained; and the existing association between the degree of clinical severity of GBS at discharge and ideal medical treatment (IVIG $1 \mathrm{~g} / \mathrm{kg} /$ day for 2 days).

It was determined that there are 3.8 times higher risk of clinical severity in those patients who do not receive the ideal medical treatment (IVIG dose of $1 \mathrm{~g} / \mathrm{kg} /$ day for 2 days).

\section{Discussion}

In the present study, we found predominance of patients with GBS, an inflammatory demyelinating variant, as has been demonstrated in international studies.

Of the 24 patients, according to the clinical evolution during the in-hospital stay, $16.7 \%$ (4 patients) required assisted mechanical ventilation due to respiratory and bulbar muscle involvement, reporting an average of

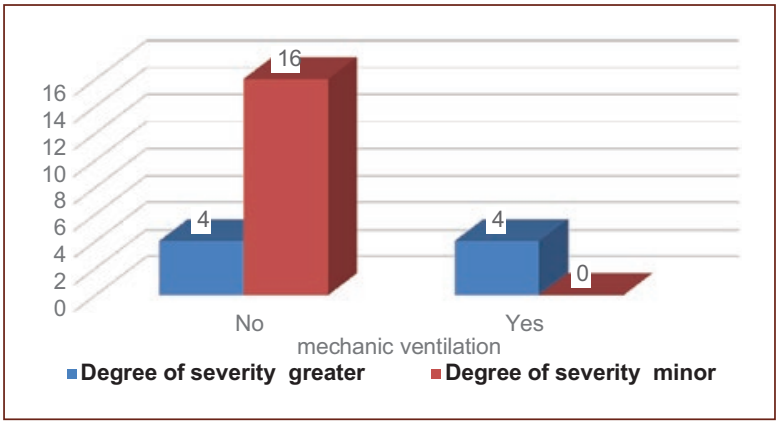

Figure 3. Frequency of patients according to the association between the degree of clinical severity of Guillain-Barré syndrome and the support of mechanical assisted ventilation (source: Clinical record. Legaria Pediatric Hospital. Secretariat of Health of Mexico City).

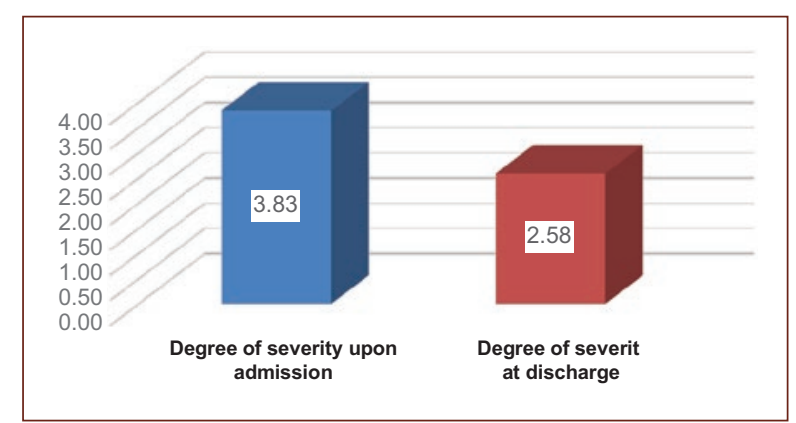

Figure 4. Comparison of the degree of severity at the patient's admission and discharge. Student's $t=5.933$, with $\mathrm{p}<0.01$, there is a significant difference (source: Clinical record. Legaria Pediatric Hospital. Secretariat of Health of Mexico City).

Table 1. Association between the degree of clinical severity of GBS and the support of mechanical assisted ventilation

\begin{tabular}{|l|c|c|c|}
\hline \multirow{2}{*}{$\begin{array}{l}\text { Association between degree of severity } \\
\text { of GBS and mechanical ventilation }\end{array}$} & \multicolumn{2}{|c|}{$\begin{array}{l}\text { Mechanic } \\
\text { ventilation }\end{array}$} & \multirow{2}{*}{ Total } \\
\cline { 2 - 3 } & No & Yes & \\
\hline $\begin{array}{l}\text { Degrees of severity } \\
\text { Greater } \\
\text { Minor }\end{array}$ & 4 & 4 & 8 \\
\hline Total & 16 & 0 & 16 \\
\hline
\end{tabular}

Chi-square $9.60 ; p<0.01$, there is significant difference.

The degree of clinical severity of GBS is associated with the need for assisted mechanical ventilation support.

GBS: Guillain-Barré syndrome.

Source: Clinical record. Legaria Pediatric Hospital. Secretariat of Health of Mexico City.

2.25 days between the onset of the manifestations clinics of GBS and the need for support with mechanical 
Table 2. Relationship between the degree of clinical severity of GBS on admission and hospital discharge (A) and test of matched samples according to the degree of clinical severity of SGB on admission and hospital discharge (B)

\begin{tabular}{|c|c|c|c|c|c|c|c|c|}
\hline \multicolumn{9}{|c|}{ (A) } \\
\hline Clinical severity & \multicolumn{2}{|c|}{ Mean } & n & \multicolumn{2}{|c|}{ Standard deviation } & \multicolumn{3}{|c|}{ Standard error average } \\
\hline Degree of severity on entry & \multicolumn{2}{|c|}{3.83} & 24 & \multicolumn{2}{|l|}{0.761} & \multicolumn{3}{|c|}{0.155} \\
\hline Degree of severity at discharge & \multicolumn{2}{|c|}{2.58} & 24 & \multicolumn{2}{|l|}{1.412} & \multicolumn{3}{|c|}{0.288} \\
\hline \multicolumn{9}{|c|}{ (B) } \\
\hline \multirow[t]{3}{*}{ Clinical severity } & \multicolumn{5}{|c|}{ Paired differences } & \multirow[t]{3}{*}{$\mathbf{T}$} & \multirow[t]{3}{*}{ gl } & \multirow{3}{*}{$\begin{array}{c}\text { Sig. } \\
\text { (bilateral) }\end{array}$} \\
\hline & \multirow[t]{2}{*}{ Mean } & \multirow[t]{2}{*}{$\begin{array}{l}\text { Standard } \\
\text { deviation }\end{array}$} & \multirow[t]{2}{*}{$\begin{array}{l}\text { Standard error } \\
\text { average }\end{array}$} & \multicolumn{2}{|c|}{$\begin{array}{l}95 \% \text { confidence interval } \\
\text { of the difference }\end{array}$} & & & \\
\hline & & & & Lower & Higher & & & \\
\hline $\begin{array}{l}\text { Degree of severity on entry-degree } \\
\text { of severity at discharge }\end{array}$ & 1.250 & 1.032 & 0.211 & 0.814 & 1.686 & 5.933 & 23 & 0.000 \\
\hline
\end{tabular}

GBS: Guillain-Barré syndrome.

Source: Clinical record. Legaria Pediatric Hospital. Secretariat of Health of Mexico City.

ventilation according to the patient's clinical conditions (range 4 days, minimum 1 day, and maximum 5 days).

Of the four patients who needed assisted mechanical ventilation, the average duration of ventilatory support was 29.75 days (range 13 days, minimum 23 days, and maximum 36 days).

Of the four patients who required mechanical ventilatory support, one patient required orotracheal intubation without requiring tracheostomy and/or gastrostomy due to clinical hospital improvement after administration of IVIG, presenting adequate suction and swallowing reflex and absence of respiratory distress.

Another patient required a tracheostomy due to the respiratory condition but without needing gastrostomy since the clinical evolution was favorable and allowed her to wean from the mechanical ventilatory support. In this way, two patients required surgical intervention with tracheostomy and gastrostomy due to poor clinical hospital evolution, with subsequent weaning of the ventilator after a long inpatient stay. Therefore, of the four patients, only three patients who required a tracheostomy $(75 \%)$ required additional oxygen support at home.

Nearly $20.8 \%$ of pediatric patients with GBS (five patients) developed hospital-acquired infection characterized by pneumonia associated with health care.

The degree of clinical severity of GBS as a risk factor for assisted mechanical ventilation was determined in the study. Of the 24 patients, eight patients (33.3\%) were classified in the group of greater degree of severity of GBS (Grades IV, V, or VI established by the
Hughes severity scale) and 16 patients (66.6\%) belonged to the group of degree of minor severity of SGB (Grades 0, I, II, and III established by the Hughes severity scale).

Of the eight patients with greater severity of GBS, only $50 \%$ of them required assisted mechanical ventilation. Being that the 16 patients with a lower degree of severity of GBS, did not require any type of assisted mechanical ventilation. Establishing that there is a significant difference; therefore, there is an association between the degree of clinical severity and assisted mechanical ventilation (Table 1).

In addition, the existing association between the degree of clinical severity of GBS on admission and ideal medical treatment (IVIG $1 \mathrm{~g} / \mathrm{kg} /$ day for 2 days) was obtained; and the existing association between the degree of clinical severity of GBS at discharge and ideal medical treatment (IVIG $1 \mathrm{~g} / \mathrm{kg} /$ day for 2 days). With an estimated risk of 3.8 times greater clinical severity in those patients who do not receive the ideal medical treatment (IVIG dose of $1 \mathrm{~g} / \mathrm{kg} /$ day for 2 days) in a timely manner and warrants more mechanical ventilatory support and subsequent complications.

The results of the present study could not be analyzed with results of other works performed in pediatric patients with GBS, since in Mexico there are only studies focused on the study of GBS in adult patients, for which we have no previous reference to integrate an opportune analysis.

This study has certain limitations, since it is of a retrospective and observational type, but with the 
obtained results, it is a matter of encouraging in each one of the health professionals, in the realization of new investigations of the GBS in pediatric patients with a prospective nature. To establish which clinical variant is most prevalent in the Mexican population studied and establish the associated complications, making an opportune diagnosis that influences the prognosis and management of GBS, since the treatments recommended by international guidelines, with plasmapheresis or IVIG, they have a high economic cost and a therapeutic efficiency not yet demonstrated in the Mexican pediatric population.

The present work was carried out with the purpose of describing clinical severity in pediatric patients with GBS, since at the national level; there are no studies that allow us to know an adequate statistics of this disease.

The Legaria Pediatric Hospital in Mexico City is a second-level center for health care and a reference for pediatric patients with neurological diseases.

The GBS is a national health problem that requires costly treatment in addition to generating large sequelae and complications subsequent to the discharge of medical care.

\section{Conclusions}

In most hospitals in Mexico, the main limitation is the lack of availability of the ideal treatment in several diseases. Therefore, it would be transcendental to have the necessary resources to offer adequate diagnosis and treatment of GBS, to reduce subsequent complications of the underlying pathology, improving the quality of life and prompt reintegration of patients to their daily activities.

\section{Conflicts of interest}

The authors declare that in this study, there are no relevant conflicts of interest.

\section{Funding}

There was no particular funding source for this scientific report.

\section{Ethical disclosures}

Protection of human and animal subjects. The authors declare that no experiments were performed on humans or animals for this study.
Confidentiality of data. The authors declare that no patient data appear in this article.

Right to privacy and informed consent. The authors declare that no patient data appear in this article.

\section{References}

1. Arnason GB, Soliven V. Acute inflammatory demyelinating poliradiculoneuropathy. In: Dick PJ, Thomas PK, Griffin JW, Low PA, Podulso JF, editors. Peripheral Neuropathy. $3^{\text {th }}$ ed. Philadelphia, PA: WB Saunders; 1993. p. 1437-97.

2. Agrawal S, Peake D, Whitehouse WP. Management of children with Guillain-Barré syndrome. Arch Dis Child Educ Pract Ed. 2007:92:161-8.

3. Landry O. Note sur la paralyse ascendante aigué. Gas Hebd Med Chir. 1859;2:472-4.

4. Guillain G, Barré JA, Strohl A. Sur un syndrome de radiculoneurite avec hyperalbunimose du liquide céphaloraquidien sans reactivon cellulaire remarques sur les caractères cliniques et graphiques des reflexes tendineux. Bull Soc Med Hôp Paris. 1916;40:146-70.

5. Asbury AK, Cornblath DR. Assessment of current diagnostic criteria for Guillain-Barré syndrome. Ann Neurol. 1990;27 Suppl: S21-4.

6. Jones HR Jr. Guillain-Barré syndrome: perspectives with infants and children. Semin Pediatr Neurol. 2000;7:91-102.

7. Beghi E, Kurland LT, Mulder DW, Wiederholt WC. Guillain-Barré syndrome. Clinicoepidemiologic features and effect of influenza vaccine. Arch Neurol. 1985;42:1053-7.

8. Secretaría de Salud, Dirección General de Epidemiología G. Documento del Comité Consultivo Nacional Para la Vigilancia Epidemiológica. Secretaría de Salud; 1998.

9. Lu JL, Sheikh KA, Wu HS, Zhang J, Jiang ZF, Cornblath DR, et al. Physiologic-pathologic correlation in Guillain-Barré syndrome in children. Neurology. 2000;54:33-9.

10. Vázquez CJ, Barré G. Sistema Nacional de Vigilancia Epidemiológica. Sist Único Inf México. 1996;13:1-2.

11. González RA, Marín OR, Rodríguez PM. Vigilancia Epidemiológica de la Parálisis Flácida Aguda en el INP. Trabajo Presentado en el VI Foro Anual de Investigación Científica, 4-6 Sep. INP; 1996.

12. Jacobs $B C$, Rothbarth $P H$, van der Meché FG, Herbrink $P$, Schmitz PI, de Klerk MA, et al. The spectrum of antecedent infections in Guillain-Barré syndrome: a case-control study. Neurology. 1998;51:1110-5.

13. Jackson BR, Zegarra JA, López-Gatell H, Sejvar J, Arzate F, Waterman S, et al. Binational outbreak of Guillain-Barré syndrome associated with Campylobacter jejuni infection, Mexico and USA, 2011. Epidemiol Infect. 2014;142:1089-99

14. Islam Z, Jacobs BC, van Belkum A, Mohammad QD, Islam MB, Herbrink $P$, et al. Axonal variant of Guillain-Barre syndrome associated with Campylobacter infection in Bangladesh. Neurology. 2010;74:581-7.

15. Fokke C, van den Berg B, Drenthen J, Walgaard C, van Doorn PA, Jacobs BC. Diagnosis of Guillain-Barré syndrome and validation of Brighton criteria. Brain. 2014;137:33-43.

16. Roodbol J, de Wit MC, Walgaard C, de Hoog M, Catsman-Berrevoets CE, Jacobs BC. Recognizing Guillain-Barre syndrome in preschool children. Neurology. 2011;76:807-10.

17. Mogale KD, Antony JH, Ryan MM. The pharyngeal-cervical-brachial form of Guillain-Barré syndrome in childhood. Pediatr Neurol. 2005;33:285-8.

18. Newswanger DL, Warren CR. Guillain-Barré syndrome. Am Fam Physician. 2004:69:2405-10

19. Tsang RS, Valdivieso-Garcia A. Pathogenesis of Guillain-Barre syndrome. Expert Rev Anti Infect Ther. 2003;1:597-608.

20. Yuki N, Susuki K, Koga M, Nishimoto Y, Odaka M, Hirata K, et al. Carbohydrate mimicry between human ganglioside GM1 and Campylobacter jejuni lipooligosaccharide causes Guillain-Barre syndrome. Proc Natl Acad Sci U S A. 2004;101:11404-9.

21. Kuijf ML, Geleijns K, Ennaji N, van Rijs W, van Doorn PA, Jacobs BC Susceptibility to Guillain-Barré syndrome is not associated with CD1A and CD1E gene polymorphisms. J Neuroimmunol. 2008;205:110-2.

22. Willison HJ, Veitch J, Paterson G, Kennedy PG. Miller Fisher syndrome is associated with serum antibodies to GQ1b ganglioside. J Neurol Neurosurg Psychiatry. 1993;56:204-6.

23. Chiba A, Kusunoki S, Obata H, Machinami R, Kanazawa I. Ganglioside composition of the human cranial nerves, with special reference to pathophysiology of Miller Fisher syndrome. Brain Res. 1997;745:32-6.

24. Yoshino $\mathrm{H}$, Harukawa $\mathrm{H}$, Asano $A$. IgG antiganglioside antibodies in Guillain-Barré syndrome with bulbar palsy. J Neuroimmunol. 2000; 105:195-201.

25. Asbury AK. New concepts of Guillain-Barré syndrome. J Child Neurol. 2000;15:183-91 
Rev Mex Neuroci. 2020;21(1)

26. Hughes RA, Cornblath DR. Guillain-Barré syndrome. Lancet. 2005;366 1653-66.

27. Wakerley BR, Yuki N. Mimics and chameleons in Guillain-Barré and Miller Fisher syndromes. Pract Neurol. 2015:15:90-9.

28. Feasby TE, Hahn AF, Brown WF, Bolton CF, Gilbert JJ, Koopman WJ. Severe axonal degeneration in acute Guillain-Barré syndrome: evidence of two different mechanisms? J Neurol Sci. 1993;116:185-92.

29. Raphaël JC, Chevret S, Hughes RA, Annane D. Plasma exchange for Guillain-Barré syndrome. Cochrane Database Syst Rev. 2002;2:CD001798.

30. Hughes RA, Swan AV, van Doorn PA. Intravenous immunoglobulin for Guillain-Barré syndrome Cochrane Database Syst Rev. 2012·7:CD002063.

31. Cruse RP. Treatment of Guillain-Barré Syndrome in Children; 2007. Available from: http://www.uptodate.com.

32. Korinthenberg R, SchessI J, Kirschner J, Mönting JS. Intravenously administered immunoglobulin in the treatment of childhood Guillain-Barré syndrome: a randomized trial. Pediatrics. 2005;116:8-14.

33. Willison $\mathrm{HJ}$, Jacobs BC, van Doorn PA. Guillain-Barré syndrome. Lancet. 2016;388:717-27.
34. Randomised trial of plasma exchange, intravenous immunoglobulin, and combined treatments in Guillain-Barré syndrome. Plasma exchange/sandoglobulin guillain-barré syndrome trial group. Lancet. 1997;349:225-30.

35. Shahar E, Leiderman M. Outcome of severe Guillain-Barré syndrome in children: comparison between untreated cases versus gamma-globulin therapy. Clin Neuropharmacol. 2003;26:84-7.

36. van Doorn PA, Kuitwaard K, Walgaard C, van Koningsveld R, Ruts L, Jacobs BC. IVIG treatment and prognosis in Guillain-Barré syndrome. J Clin Immunol. 2010;30 Suppl 1:S74-8.

37. Rajabally YA, Uncini A. Outcome and its predictors in Guillain-Barre syndrome. J Neurol Neurosurg Psychiatry. 2012;83:711-8.

38. Legido A, Tenembaum SN, Katsekos CD, Menkes J. Autoimmune and postinfectious diseases. In: Menkes J, Sarnat HB, María BL, editors. Child Neurology. $7^{\text {th }}$ ed. Philadelphia, PA: Lippincott Williams and Wilkins; 2006. p. 557-657.

39. Darweesh SK, Polinder S, Mulder MJ, Baena CP, van Leeuwen N, Fran$\mathrm{co} \mathrm{OH}$, et al. Health-related quality of life in Guillain-Barré syndrome patients: a systematic review. J Peripher Nerv Syst. 2014;19:24-35 